\title{
EDITORIAL
}

\section{Role of journal clubs in undergraduate medical education in India}

\author{
Mahanta Putul*
}

A journal club is a group of people who meet regularly to critically evaluate recent articles in the academic literature, such as the literatures in the medical field and other scientific areas. It helps in simplifying the application of evidence-based medicine to some other areas of medical practice. Participants in journal club can express their views about the appropriateness on the research questions, hypothesis, design and statistical analysis of the article discussed.

Clinical research gives us the insight to learn to prevent, diagnose, and treat illnesses, hence directly impacting people's health. It involves different elements of scientific investigation and human participation. Training in clinical research, ${ }^{1}$ therefore, highlights the extent of needs for research-oriented medical education throughout the country which is an important need at the present juncture. There is a need to involve the undergraduate medical students in rigorous research activities at the medical colleges and universities to improve the research-oriented medical education where journal club may play an active role.

\section{THE CURRENT SCENARIO IN INDIA}

India has a history of scientific research and publications. Big debates are going on among the scientists, researchers and educators in the field of scientific research and publication. Considering the population growth, publications and patent production in India were marginally low as compare to other developing and developed country. ${ }^{2}$ Irrespective of research subjects, a total of 157 researchers per million populations were reported in India in in the year 2010, much less than the global average of $1023 .{ }^{3}$ As far as research in medical sciences is concerned, India raised with $12^{\text {th }}$ position among the productive countries of the world in medicine during 1999 to 2008 with a simple $1.6 \%$ share in the world research output. ${ }^{4}$ In the year 2015 India ranked $5^{\text {th }}$ position in the production of the publication. The USA, China, United Kingdom, and Germany are in the leading position. ${ }^{2}$ But, most of these researches of India were the faculty members and scientists from reputed medical institutes, and very little had been contributed by students. ${ }^{5}$ Interesting fact is that in India out of 10,000 research efforts, only 4 comes out as a succesful researcher, India ranks below Kenya, Chile, Brazil, and China.

Investment in research and development in India is very poor, which is only $0.9 \%$ of its GDP, whereas China, Russia, and Brazil spend more on it than India. ${ }^{2}$

Therefore, the needs of the undergraduate biomedical research (BMR) in India is to be reinforced with all keenness, at the time while the BMRs of faculties are striving stiff to get momentum among the medical colleges in India. It is a fact that cost implications often become the limiting factor in exposing undergraduate students to large scale clinical trials in resource-limited scenario besides other facilities. Therefore, we need some alternative approaches to stimulate critical appraisal skills among medical students who are going to be a future researcher.

EVOLUTION OF SCIENTIFIC PUBLISHING: KEY DATES $^{6}$

KEY YEARS

1323

1660

1665 First scientific journal was published, i.e., Journal des Scavans and Philosophical Transactions of the Royal Society of London. The journal used some form of peer review system, although not exactly like today's version.

1731 Medical Essays and Observations, the first fully peer-reviewed journal was launched by the Royal Society of Edinburgh.

1743 The American Philosophical Society, the first scholarly society in what is now the US, is created.

1820 First specialist journal was published.

1848 The American Association for the Advancement of Science (AAAS) was founded. AAAS publishes the journal Science and is the largest general scientific society in the world.

1869 Nature publishes its first issue. 


\section{Key Evoluation of scientific publishing \\ years}

1870

References began to be collected at the end of the articles.

1880 Science publishes its first issue.

1920 First summaries appeared at the end of the article.

1930 First paper on the use of statistics was published.

1947 Elsevier, the longtime publishing giant, launches its first international journal, Biochimica et Biophysica Acta.

1950 Widespread use of IMRAD format.

1960 Summaries began to be collected at the end as an abstract.

1970 Database was introduced.

1980 First international conference on peer-review was organized.

1990 Introduction of electronic journal was initiated. Postmodern Culture becomes the first online journal.

1991 arXiv, the science pre-print server was launched.

2003 The Public Library of Science (PLOS) was founded.

2006 PLOS ONE, the wildly successful open access megajournal, begins publishing.

2013 PLOS ONE publishes 31,500 articles.

2010 The altmetrics manifesto, describing potential new ways to gauge the impact of research beyond citations and impact factors was written.

2012 Several innovative and relatively new journals, including F1000 Research, Peer J, and eLife, are launched. These journals are experimenting with new forms of peer review, new business models and new funding sources.

The above data shows how the scientific society was formed with the defined objectives for promoting cooperation among scientists in different fields, defending scientific freedom, encouraging scientific responsibility, supporting scientific education and science to outreach for the betterment of the society.

Journal club is one of such tools that can enrich the scientific literature and help in improving medical education in the era of evidence based medicine. The credit for the establishment of the first formal medical journal club goes to William Osler, who founded the journal club at the McGill University in North America in 1875. ${ }^{7}$

\section{ROLE OF JOURNAL CLUB}

A journal club among undergraduate students will help them to develop and to increase the inquisitiveness about scientific reading. Picking up an article for discussion will surely build the critical thinking capacity in the young minds. This will increase their competency in application of theoretical principle and basic doctrine of research. Once they are acquainted with the process of reading scientific articles, they will develop the curiosity about novelty on the subjects which ultimately will build a group of future researchers. Medical science is an evolving entity and our clinical practice should corner around Evidence Based Medicine.

'Evidence-based Health Care (EBHC)' could best be integrated with medical student training to enhance student's knowledge, attitude, and skills regarding EBHC. In the era of evidence based medicine, analyzing the quality, validity, and relevance of the evidence should be a skill that must be taught from undergraduate level ${ }^{7}$ to improve the standard of medical education in India and journal club can be used for this objective.

Understanding the reading habits of medical students of scientific journal provide insights and opportunities for medical educators to evaluate the learning needs of the students and improve the teaching methods. Many of us read scientific journal for some specific reason.

Some of the common reasons why people read a scientific journal are as follows:

- To impress

- To learn clinical features and causes

- To distinguish useful from harmful

- To keep abreast of professional news

- Whether to use a new or existing diagnostic test, etc.

Medical literature is continuously mounting in all of its areas. The concepts, ideas, and beliefs in different fields are undergoing a rapid revolution. Therefore, academicians, researchers, practitioners, and students to keep updated knowledge on the subject. So, the benefits of a journal club can be used to remain current with the medical literature which offers an opportunity to learn methods of critically evaluating journal articles. It can be organized around a defined subject in basic or applied research.

The activities of a journal club are commonly seen in postgraduate medical education in India; however, it is relatively underused in undergraduate medical education. It can be a very effective platform where the students can gather first-hand knowledge on analyzing, evaluating, dissecting, and utilizing the scientific literature.

Journal clubs and letter writing exercises are innovative ways of teaching critical appraisal to medical undergraduates, and the response from the students have also been positive. ${ }^{8,9} \mathrm{It}$ motivates reading behaviors of physicians-in-training and also increase knowledge of epidemiology and biostatistics. ${ }^{10}$ Undergraduates can plan, structure sessions with well-defined learning objectives, suitably designed to evoke participants ${ }^{2}$ interest and attendance which are essential to the functioning of a journal club. ${ }^{11}$

The evaluation of the journal clubs can be done through periodic internal assessment and evaluation tests. The number of correspondences through letters to the editor, getting 
accepted for publication, based on the specific questions remaining unanswered regarding the original articles discussed may also be an indicator of the efficacy of the club.12

Subsequent discussions of journal club on receipt of reply from the editor or author to a published letter to the editor or article in a subsequent session, enhances the insight on the topic further.

Epidemiology and biostatistics are generally taught under the Community Medicine subject during the period of $3^{\text {rd }}$ professional MBBS Part-1 to Indian Medical Graduates. As the knowledge of biostatistics is essential in biomedical research and publications and since by the time a student enters $3^{\text {rd }}$ professional tenure they possess appreciable knowledge on biostatistics, journal clubs can be introduced at this stage onward which will be more meaningful ${ }^{7}$ and effective.

The quality of a research paper can be measured by their citation index. Currently, India is lagging behind in citation index as compared to other leading countries. ${ }^{2} \mathrm{~A}$ journal club helps in doing quality research and its subsequent publication.

Many of us may be arguing about the feasibility of conducting journal clubs for huge batches of undergraduates, but the problems may be overcome by using the tutorial or discussion classes in smaller batches.

\section{CONCLUSION}

Making journal clubs part of the medical curriculum may thus benefit the purpose of exposure of students to the world of frontline research, and pave their way for a future entry in the world of translational research.

Source of funding: None declared.

Conflict of interest: None Declared.

\section{REFERENCES}

1. Aggarwal S, Singh H, Bansal P, Goyal A, Saminder Singh $\mathrm{K}$. Training in clinical research in India. Indian $\mathrm{J}$ Community Med 2010;35:446.

2. Putta chandra Prabhakar. Current scenario of scientific research and publication in India. Healthminds [online]
2017 Jan 16 [cited 2019 June 20]; Available from: URL:http://healthminds.in/blog/current-scenario-ofscientific-research-and-publication-in-india/

3. United Nations Educational, Scientific and Cultural Organization. Institute for Statistics. Country profiles: India. Human resources in research and experimental development (RandD). [cited 2019 June 20]; Available from: URL:http://www.uis. unesco.org/DataCentre/ Pages/countryprofile.aspx? regioncode $=40535$ andcode $=$ IND

4. Gupta BM, Bala A. Scientometric analysis of Indian research output in medicine during 1999-2008. J Nat Sci Biol Med 2011;2:87-100.

5. Wickramasinghe DP, Perera CS, Senarathna S, Samarasekera DN. Patterns and trends of medical student research. BMC Med Educ 2013;13:175.

6. Mudrak Ben. Scholarly publishing: a brief history. AJE Scholar [online]. [cited 2019 June 20]; Available from: URL:https://www.aje.com/arc/scholarly-publishingbrief-history/

7. Biswas Tamoghna. Role of journal clubs in undergraduate medical education. Indian J Community Med 2011 Oct-Dec;36(4):309-10.

8. Edwards R, White M, Gray J, Fischbacher C. Use of a journal club and letter-writing exercise to teach critical appraisal to medical undergraduates. Med Educ 2001;35:691-4.

9. Green BN, Johnson CD. Use of a modified journal club and letters to editors to teach critical appraisal skills. J Allied Health 2007;36:47-51.

10. Linzer M, Brown JT, Frazier LM, DeLong ER, Siegel WC. Impact of a medical journal club on house-staff reading habits, knowledge, and critical appraisal skills. A randomized control trials. JAMA 1988;260:2537-41.

11. Valentini RP, Daniels SR. The journal club. Postgrad Med J 1997;73:81-5.

12. Sandifer QD, Lo SV, Crompton PG. Evaluation of a journal club as a forum to practise critical appraisal skills. J R Coll Physicians Lond 1996;30:520-2.

Address for correspondence:

*Editor-in-chief

Int J Health Re Medico Leg Prac

Professor and Head, Forensic Medicine and Toxicology

Assam Medical College, Dibrugarh, Assam

Email: drpmahanta@gmail.com

Mobile: +919435017802 